\title{
The Research on the Relationship between University Students' Employment Abilities and Social Demands in Jiangsu Province
}

\author{
Chunyan Wang \\ Jiangsu Vocational Institute of Commerce, Nanjing 211168, China \\ Wangqiao-1977@163.com
}

\begin{abstract}
There is a close relationship between the employment abilities of college students and social needs in Jiangsu Province. This paper uses the method of empirical research and uses SPSS21.0 for questionnaire analysis. The research results show that the employment abilities of college students in Jiangsu Province are composed of three dimensions: core competence, broad ability and all-inclusive ability. The social demands consist of two dimensions: job response and career development. The core competence, broad ability, and all-inclusive ability of college students in Jiangsu Province are significantly related with their social needs. Through the above analysis, this paper proposes to improve the matching degree between the employment abilities of college students in Jiangsu Province and the social needs from constructing collaborative platform, optimizing talent-training plan, strengthening social ties, improving self-confidence, and designing career planning.
\end{abstract}

Keywords: college students in Jiangsu; employment abilities; employment social demand; relationship research.

\section{Introduction}

In the current Chinese labor market, the "difficult employment" of college students in Jiangsu Province and the "difficulties in recruitment" has always been a problem that plagued the government, and has even caused great confusion for the development of higher education in the province. Combining the clusters characteristics of Jiangsu university and high-tech enterprise, constructing employment capacity structure model of Jiangsu college students and talent capacity demand model of high-tech enterprises in Jiangsu Province, has a great guiding significance for how to reduce the frictional unemployment of college students, reduce unemployment problem after graduation, and improve matching degree of the unemployment and vacancies.

\section{Concept Definition and Model Construction}

\subsection{Definition of College Students' Employment Ability}

With the development of economy and society, research focus about employment-ability has shifted from studying the employment attitude of the unemployed to promoting the employment of all employees, and then shifting to the needs of employers for the "meta-features" of employees from the enterprise and organizational levels. According to Thijssen's research, employability can be analyzed from three levels, including the core level, the broad level and the all-inclusive level. The core level refers to the individual capabilities of workers, which enable workers to gain a competitive advantage in the labor market. Broad level refers to the worker's ability to learn and work and the basic ability to be competent for work. The all-inclusive level mainly refers to the environmental factors and realizing conditions affecting the employment of workers.

The employment ability of college students in Jiangsu Province, studied in this paper, refers to the knowledge, skills, personality characteristics and external influence environment for university students in Jiangsu Province to gain job positions in labor market. 


\subsection{Definition of the Social Needs of College Students in Jiangsu Province}

The employment social demand is mainly based on the targets of these employers when recruiting employees. In the process of recruiting employees, employers seek to maximize utility. Therefore, in the case of a certain cost, the employers, by setting the application conditions and work response, recruits employees who meet their production and service needs as much as possible. With the acceleration of industrial upgrading, the employment conditions and job response set by employers are also constantly improving.

The employment social needs of college students in Jiangsu Province, discussed in this paper, are mainly to study whether there is any difference between the employer's application conditions and the job response and the career development model of the university when recruiting employees. If existing, how much are these difference between them.

\subsection{University Students' Employment Ability and Employment Social Needs in Jiangsu Province}

With regard to the study about the relationship between employ-ability and social labor demand, the most representative study abroad is to use method of labor market analysis, from the perspective of studying unemployment rate. The most representative ones are the job search theory and matching model of three Nobel Prize winners, Diamond, Mortensen and Pizarides. The three scholars have constructed the equilibrium search theory and matching model, and explained the job-seeking strategies of job seekers, the influencing factors of job search intensity, and how the job seekers and the enterprise demanders to match in the "market friction" environment.

Studying the employment problem of college students from the perspective of job search has also attracted the attention of domestic scholars. The main feature is to study the characteristics of job search behavior. For example, He Yiming and Zhu Weiping gave an overview of the characteristics of Chinese college students' job search behavior, which boiled down to "long cycle, high density, high cost, low efficiency, and informal channels". Xie Yong and Li Wei's research confirmed that students in Nanjing, internship experience and human expenditure could reduce the search time, while the birth in the city and higher retention wages will increase the search time. Compared with foreign studies emphasizing theoretical system construction and analysis, domestic research focuses more on phenomena research and cross-sectional data for empirical analysis.

\subsection{Theoretical Model Construction}

The research object in this paper is the university students in Jiangsu Province. The relationship between the employment ability of college students in Jiangsu Province and the social needs of employment is the main line of research. Based on the interviews of certain scales and questionnaires, the paper studies the impact and its mechanism of action on the demand for employment caused by the employment capacity of college students in Jiangsu Province under the new normal conditions. Based on the research content the following assumptions are proposed.

H1: The employment ability of college students in Jiangsu Province is composed of core competence, broad ability and all-inclusive ability dimension;

H2: The employment social needs of college students in Jiangsu Province are composed of matching dimensions between job response and career development;

H3: The various dimensions of employment capacity of college students in Jiangsu Province are significantly related to the employment social needs.

According to the relevant research literature and theoretical assumptions, the conceptual model of this study is determined, as shown in Figure 1 below. 


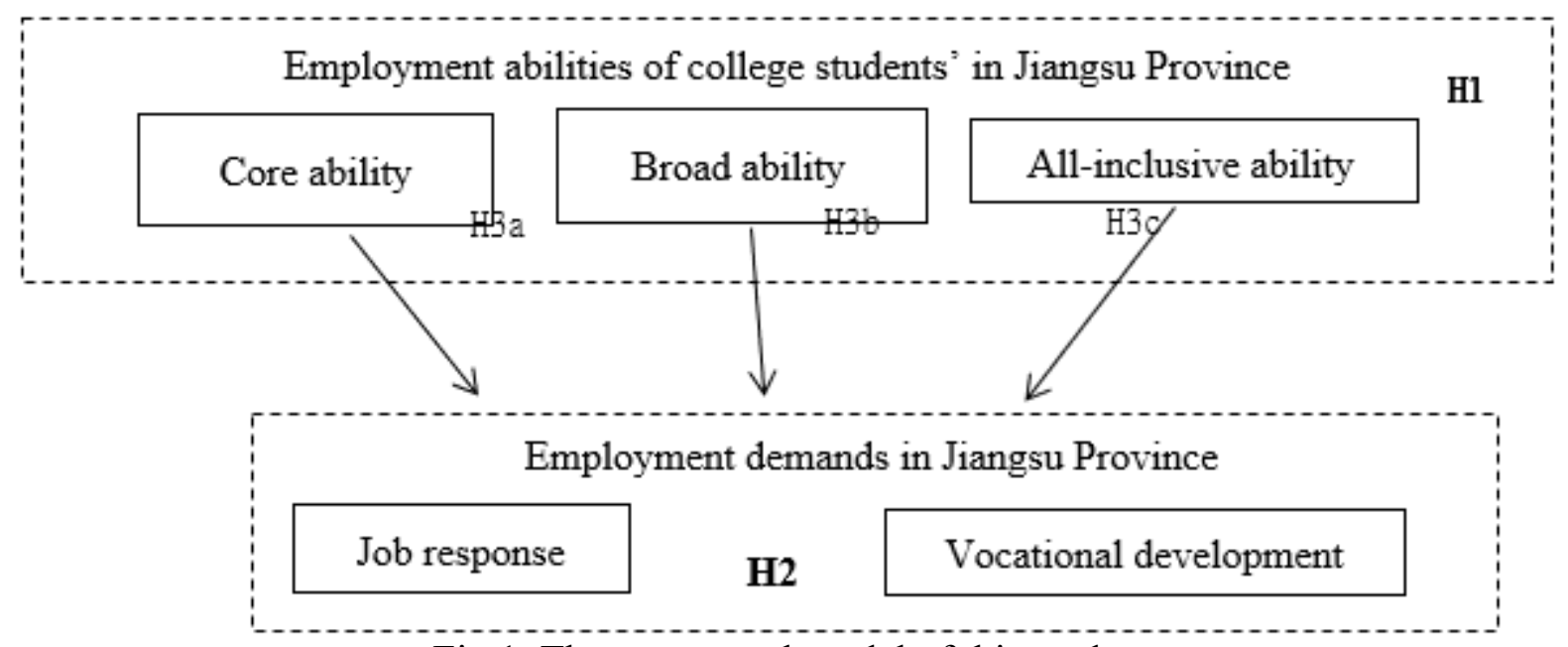

Fig 1. The conceptual model of this study

\section{Research Design and Variable Measurement}

\subsection{Scale Development of University Students' Employment Ability and Social Demand in Jiangsu Province}

This study draws on more mature scales at home and abroad, and makes appropriate corrections in combination with the research purposes. The employment ability evaluation scale with items was constructed, as shown in Table 1; the matching measure scale of employment ability of college students in Jiangsu Province was constructed, and the items were 6, as shown in Table 2.

\subsection{Sample Selection and Data Acquisition}

The sample survey of this report considers the regional differences and data feasibility of Jiangsu Province. The universities in Nanjing, Wuxi and Xuzhou were selected as the research areas to conduct a questionnaire survey for college students in Jiangsu Province. This questionnaire was conducted in the form of online research, and 233 copies were collected, including 12 invalid questionnaires and 221 valid questionnaires, with an effective rate of $94.95 \%$.

Among the 233 respondents, 128 were males, accounting for 54.94\%; 105 were females, accounting for $45.06 \%$. In terms of grade level, freshmen accounted for $16.74 \%$, sophomores accounted for $17.60 \%$, juniors accounted for $22.74 \%$, and seniors accounted for $42.92 \%$.

\section{Empirical Test about the Influence of Adaptability of College Students' Employment Ability on the Matching Degree of Employment Social Needs in Jiangsu Province}

\subsection{Adaptability Analysis of College Students' Employment Ability in Jiangsu Province}

To ensure the reliability and validity of the adaptability scale of college students 'employment ability in Jiangsu Province, by SPSS21.0 statistical analysis software, this paper used orthogonal rotation method to conduct exploratory factor analysis and reliability test on the items. The results are shown in Table 1. The KMO spherical test is 0.836 and the Sig value is 0.000 , indicating that the scale is suitable for exploratory factor analysis.

The results show that items 1,2 , and 3 constitute the first factor, which effectively reflects the adaptability of core competencies that can help college students in Jiangsu stand out in their work. Therefore, the factor was named "core ability", its reliability index Cronbach's $\alpha$ value was 0.704 , and the contribution rate was $21.37 \%$.

Items 4,5 , and 6 constitute the second factor, reflecting the adaptability of the basic ability of college students in Jiangsu Province. Therefore, the factor was named "broad ability", its reliability 
index Cronbach's $\alpha$ value was 0.834 , and the contribution rate was $38.11 \%$.

The Items 7, 8, and 9 constitute the third factor, which reflects the adaptability of college students in Jiangsu Province for external environment during job search. Therefore, the factor was named "allinclusive ability", its reliability index Cronbach's $\alpha$ value was 0.845 , and the contribution rate was $30.45 \%$.

The cumulative contribution rate of the three factors is $89.93 \%$. All the above indicators have reached the test standard, indicating that the scale has good reliability and validity, and is suitable for statistical analysis and hypothesis testing.

In the choice of control variables, the study takes basic information variables of college students in Jiangsu Province respectively to do different analysis on core ability, broad ability and all-inclusive ability.

Table 1. Scale Test on Adaptability of Employment Ability of College Students' in Jiangsu Province

\begin{tabular}{|c|c|c|c|c|}
\hline \multirow[b]{2}{*}{ Items } & \multicolumn{3}{|c|}{ factors } & \multirow[b]{2}{*}{ Extraction } \\
\hline & $\begin{array}{c}\text { Core } \\
\text { ability }\end{array}$ & $\begin{array}{l}\text { Broad } \\
\text { ability }\end{array}$ & $\begin{array}{l}\text { All-inclusive } \\
\text { ability }\end{array}$ & \\
\hline $\begin{array}{l}\text { I think that the breadth of my knowledge can } \\
\text { make myself stand out in the future. }\end{array}$ & .715 & -.176 & .321 & .907 \\
\hline $\begin{array}{l}\text { I think that my innovative thinking can make } \\
\text { myself stand out in the future }\end{array}$ & .802 & -.247 & .287 & .825 \\
\hline $\begin{array}{l}\text { I think that my organizational management ability } \\
\text { can make myself stand out in the future work. }\end{array}$ & .684 & -.058 & .155 & .796 \\
\hline $\begin{array}{l}\text { I think that my interpersonal skills are capable of } \\
\text { working for the future }\end{array}$ & -.380 & .892 & .912 & .773 \\
\hline $\begin{array}{l}\text { I think that I have the ability to acquire } \\
\text { knowledge to be able to do my job in the future. }\end{array}$ & -.429 & .701 & .838 & .874 \\
\hline $\begin{array}{l}\text { I think my language skills are good for my future } \\
\text { job. }\end{array}$ & -.195 & .915 & .756 & .750 \\
\hline $\begin{array}{l}\text { I often discuss things about my future work with } \\
\text { my teachers, family, and classmates. }\end{array}$ & .176 & .130 & -.503 & .832 \\
\hline $\begin{array}{l}\text { When it comes to stress and difficulty, I usually } \\
\text { think calmly and calmly. }\end{array}$ & .216 & .263 & -.189 & .758 \\
\hline $\begin{array}{l}\text { Even if I am treated unfairly, I can keep my mood } \\
\text { calm. }\end{array}$ & .322 & .467 & -.058 & .881 \\
\hline
\end{tabular}

The results show there are significant differences in perception for adaptability of core competence among college students in different grades in Jiangsu Province $(\mathrm{P}=0.031<0.05)$. The senior college students in Jiangsu Province think that their core competence is more adaptable, while the freshmen of Jiangsu Province think that adaptability of their core competencies is low, and the difference between them is 0.256 . The results reflect that students with higher grades believe that their core competence is more adaptable.

The results show that there are significant differences in perception for adaptability of broadability among college students in different majors in Jiangsu Province $(\mathrm{P}=0.025<0.05)$. The college students in logistics think that they have higher adaptability to broad abilities, while students in management majors think that their broad ability is less adaptable, and the difference between them is 0.139 . The result reflects that those college students with stronger professional operability think that their broad ability is highly adaptable.

The results show that there are significant differences in perception for adaptability of allinclusive ability among college students in different regions in Jiangsu Province $(\mathrm{P}=0.017<0.05)$. Those students in Xuzhou area think that their all-inclusive ability is less adaptable. This shows that college students have a choice for employment areas when choosing jobs, and are greatly influenced by external factors. 


\subsection{Analysis on Employment Social Needs of College Students in Jiangsu Province}

In order to ensure the reliability and validity of the Jiangsu Social Employment Demand Scale, the exploratory factor analysis and reliability test were carried out on the scale by the orthogonal rotation method. The analysis results are shown in Table 2. The KMO spherical test is 0.758 and the Sig value is 0.000 , indicating that the scale is suitable for exploratory factor analysis.

The results show that the items 1,2, and 3 constitute the first factor, which effectively reflects the conditions and qualities that college students in Jiangsu should have when they apply for positions. Therefore, the factor is named "work response" and its reliability index. Cronbach's alpha value was 0.722 and the contribution rate was $47.19 \%$.

Item 4,5 , and 6 constitute the second factor, which reflects the matching between the future development direction of professional students in Jiangsu Province and the job response. Therefore, the factor is named "career development" and its reliability index Cronbach's $\alpha$ value is 0.791, the contribution rate was $42.28 \%$.

Table 2. Scale Test on Employment Social Needs of College Students in Jiangsu Province

\begin{tabular}{c|c|c|c}
\hline \multirow{2}{*}{ Items } & \multicolumn{2}{|c}{ Factors } & \multirow{2}{*}{ Extraction } \\
\cline { 2 - 3 } & $\begin{array}{c}\text { Work } \\
\text { response }\end{array}$ & $\begin{array}{c}\text { Career } \\
\text { development }\end{array}$ & .735 \\
\hline $\begin{array}{c}\text { Can use the knowledge learned to quickly solve practical } \\
\text { problems encountered in the work }\end{array}$ & .740 & .274 & .841 \\
\hline $\begin{array}{c}\text { When faced with work problems, can associate with } \\
\text { relevant theoretical knowledge. }\end{array}$ & .835 & .313 & .746 \\
\hline $\begin{array}{c}\text { When encountering professional and technical problems, } \\
\text { there can be a good solution. }\end{array}$ & .826 & -.106 & .801 \\
\hline $\begin{array}{c}\text { Good at summing up regular experience from work life. } \\
\text { Good at understanding and analyzing the various problems } \\
\text { encountered in the work. }\end{array}$ & -.108 & .840 & .750 \\
\hline $\begin{array}{c}\text { Always come up with and implement new ideas and new } \\
\text { ideas. }\end{array}$ & -.214 & .752 & .739 \\
\hline
\end{tabular}

The cumulative contribution of the two factors was $89.47 \%$. All the above indicators have reached the test standard, indicating that the scale has good reliability and validity, and is suitable for statistical analysis and hypothesis testing.

In the choice of control variables, the study takes the basic information variables of college students in Jiangsu Province to do w test difference between work response and career development.

The results show that there is a significant difference in perception for work response among college students in different kinds of colleges $(\mathrm{P}=0.032<0.05)$. The college students in Jiangsu undergraduate colleges have higher work response perceptions, while higher vocational (specialty) colleges have lower perceptions.

The results show that there are significant differences in perceptions for career development among college students in different grades in Jiangsu Province $(\mathrm{P}=0.028<0.05)$. The perception for career development of college students in the third and fourth grades is higher in Jiangsu Province.

\subsection{Regression Analysis on the Influence of University Students' Employment Ability on Employment Social Demand in Jiangsu Province}

In order to study mechanism of the influence about adaptability of employment ability on employment social demand in Jiangsu Province, this study takes employment social demands as the dependent variable, puts the core ability, broad ability and all-inclusive ability as the independent variables, and tests the influence of the independent variable on the dependent variable. The results are shown in Table 3. 
Table 3. Regression analysis on the impact of college students' employment ability on social demand in Jiangsu Province

\begin{tabular}{c|c|c}
\hline \multirow{2}{*}{} & \multicolumn{2}{|c}{ Employment social demands } \\
\cline { 2 - 3 } & Normalization coefficient B & Standard error of B \\
\hline Core ability & .718 & .295 \\
\hline Broad ability & .823 & .270 \\
\hline All-inclusive ability & .792 & .304 \\
\hline F & \multicolumn{2}{|c}{80.125} \\
\hline R2 & .837 \\
\hline$\Delta$ R2 & .829 \\
\hline
\end{tabular}

The results show that the independent, employment ability of college students in Jiangsu Province has a significant impact on the social needs of employment. The F value of the equation is 80.124 , and significance level is $\mathrm{P}=0.019<0.05$. It shows that the employment ability of college students in Jiangsu Province has a significant positive impact on the social needs of employment.

Specifically, in the three dimensions of employment capacity of college students in Jiangsu Province, the influence factors of core competence, broad ability, and all-inclusive ability are significant. (1) Standardization coefficient of core competence is 0.718 , and the significance level $\mathrm{P}=$ $0.026<0.05$, indicating that core competence adaptability has a significant positive impact on employment social needs. With the improvement of core competence adaptability, the social employment needs of college students in Jiangsu Province will also increase. (2) Standardization coefficient of the broad ability is 0.823 , and the significance level is $\mathrm{P}=0.011<0.05$. The adaptability of broad ability has a significant positive impact on the employment social needs of college students in Jiangsu Province. With the improvement of adaptability of broad ability, employment Social needs of college students in Jiangsu will also increase. (3) The standardization coefficient of all-inclusive ability is 0.792 , and the significance level is $\mathrm{P}=0.003<0.05$. The adaptability of all-inclusive ability has a significant positive impact on employment social needs of college students in Jiangsu Province.

The results show that compared with the core competence, the adaptability of broad ability and all-inclusive ability to the social needs of college students in Jiangsu Province are more obvious. Therefore, the important grasp to cultivate employment ability of college students' in Jiangsu Province can be placed on improving match degree between employment ability and employment social demands.

\section{Conclusions and Countermeasures}

This report takes Jiangsu University students as its research object, develops measurement scales of the employment ability and employment social needs of college students in Jiangsu Province, and tests the influence of the adapt-ability of college students' employment ability on the employment social needs of college students in Jiangsu Province through empirical research. Three conclusions are drawn.

First, there are significant differences in perception for adaptability of core competence of college students in different grades. The cultivation of the core competence of college students in Jiangsu Province should play a synergistic role and build a collaborative system between the government, universities and employers to solve problems such as information islands and high information thresholds in the old platform of employment information service, in order to improve the smoothness of employment information. At the same time, there are significant differences in perception for adaptability of broad capacity among college students in different majors. Colleges and universities should seriously study the employment ability in various positions in different industries. On this 
basis, train college students in a wide range of capacities for different professional qualification and develop a more targeted talent development program to match the needs of the increasingly employer. Moreover, there are significant differences in perceptions for the adaptability of all-inclusive ability among college students in different regions. It is necessary to increase contact between government and employers, strengthen students' contact with the society, and the arrange college students to enter enterprises for doing practice, part-job as soon as possible in order to improve the training level for all-inclusive ability of college students in Jiangsu Province.

Secondly, there are significant differences for college students in perceptions for work response in different types of schools in Jiangsu Province, indicating that undergraduate have higher selfconfidence in their ability to cope with their work. Therefore, we can improve the self-confidence of students in vocational colleges combining actual situation in each college, to cultivate their quality and ability for coping with work. At the same time, there are significant differences in perception for career development in different grades, indicating that higher grades have higher expectations for career development. Therefore, it is possible for senior college students to tailor their career planning plans according to employment direction and personal situation, helping them to make fewer detours in career choices and employment.

Thirdly, regression analysis shows that the core competence, broad ability and all-inclusive ability of college students have a significant positive impact on social needs of employment. This means that when the talent training in colleges and universities can match the needs of employers, cultivated college students can have good employability to adapt to the rising barriers for employment.

\section{Acknowledgments}

The research for this paper was supported by the Education and Science Fund of the 13th-five project of Jiangsu Province (D/2016/03/69), the Qing Lan Project, the Key Project of Jiangsu Vocational Institute of Commerce (NO. JSJM16002), Excellent Innovation Team Fund of Jiangsu University Philosophy and Social Sciences (2017ZSTD028), and Excellence Team Fund About Economic and Technological Innovation of Jiangsu Vocational Institute of Commerce. We are grateful for their supports.

\section{References}

[1]. Gong Xun, Cai Taisheng. The Employment Ability of College Students: Elements, Structure and Cultivation Path [J]. Jiangsu Higher Education, 2018(1):91-94.

[2]. Xie Fang. Discussion on the Path of Improving the Employment Ability of College Students Based on Supply Side Reform[J]. Jiangsu Higher Education, 2017(5):82-85.

[3]. Cheng Wei. An Empirical Study of College Students' Employment Ability and Its Improvement_—Based on Effective Sample Analysis of 64 Universities in China [J]. Higher Education Exploration, 2017(7):98-105.

[4]. He Ermao. Employment: The Logical Dimension of a Meta Problem [J]. Journal of Henan Normal University: Philosophy and Social Sciences, 2017(6): 138-142.

[5]. Ma Shihong.Using Supply Side Reform to Solve the Structural Contradiction of College Students' Employment Market[J]. China Higher Education, 2016(10):7-7.

[6]. $\mathrm{Xu}$ Xiaojun.Exploration of Employment Guidance Adapting to Students' Personality Development [J]. Higher Education Exploration, 2017(s1):175-176. 